\title{
Fregean Monism: A Solution to the Puzzle of Material Constitution
}

\author{
Soo Lam Wong*
}

Received: 1 October 2019 / Accepted: 24 June 2020

Abstract: The puzzle of material constitution can be expressed in at least two ways. First, how can the constituting object and the constituted object, which are materially and spatially coincident, be regarded as different objects? Second, how can the constituting object and the constituted object, which are qualitatively distinct, be regarded as identical objects? Monists argue that the constituting and constituted objects are identical since they are materially and spatially coincident and the property differences between then are simply differences in description, perspective or context. In contrast, pluralists argue that the constituting and constituted objects are not identical even if they are materially and spatially coincident since they are qualitatively distinct. This paper proposes a solution to the puzzle of material constitution called 'Fregean Monism' (FM), and shows that it can better account for the property differences between the constituting and constituted objects without the need to regard them as two distinct objects. On the FM view, the puzzle of material constitution is partly a semantic puzzle and partly a metaphysical puzzle, and shows how a solution to the semantic part of the puzzle, based on the Fregean distinction between sense and reference, can yield a satisfactory solution to the metaphysical part of the puzzle. The key idea is that while the reference of a term picks out both the

* Singapore University of Social Sciences

- Singapore University of Social Sciences, Centre for University Core, 463 Clementi Road, Singapore 599494

$\triangle$ huang_shunan@yahoo.com.sg

(C) The Author. Journal compilation (C) The Editorial Board, Organon F.

This article is distributed under the terms of the Creative Commons Attribution-NonCommercial 4.0 International Public License (CC BY-NC 4.0). 
referent object and referent properties, the sense of the term determine which referent properties are picked out.

Keywords: Constitution; Fregean; identity; monism; pluralism; reference; sense.

\section{Introduction}

Material constitution is a one-one or whole-whole relation. It concerns the relation of one object (for example, a piece of bronze) constituting another object (for example, a bronze statue) where both the constituting and the constituted objects are materially and spatially coincident. The puzzle of material constitution can be expressed in at least two ways. First, how can the constituting object and the constituted object, which are materially and spatially coincident, be regarded as different objects? Second, how can the constituting object and the constituted object, which are qualitatively different, be regarded as identical objects? In contrast, material composition is a many-one or part-whole relation. It concerns the relationship of two or more objects (for example, two or more pieces of bronze) constituting a further object (a bronze statue) where both the constituting object and the constituted object share at least some of the same material parts. As this paper is about the puzzle of material constitution, and not material composition, I shall not discuss problems arising from material composition further.

Solutions to the puzzle of material constitution can be divided into two broad camps. The first camp claims that material constitution is simply identity (for example, the piece of bronze constituting the bronze statue is identical to the bronze statue). As the piece of bronze and the bronze statue are materially and spatially coincident, they are identical. In contrast, the second camp claims that material constitution is not identity despite their material and spatial coincidence (for example, the piece of bronze constituting the statue is not identical to the bronze statue) because they do not share all of the same properties (for example, the bronze statue, but not the piece of bronze, possesses aesthetic appeal). Following Kit Fine (2003), I shall label the first camp monism and the second camp pluralism. In holding that the constituting and constituted objects are identical, pluralist 
critics claim that monism cannot account for how they have different properties. And in holding that the constituting and constituted objects are distinct, monist critics claim that pluralism cannot account for why there can be two or more materially and spatially coincident objects.

My sympathy lies with the monist camp. However, I agree with the pluralist critics that if the constituting and constituted objects are identical, their qualitative differences have to be explained, and not explained away as mere differences in description, perspective, or context. And I propose a version of monism called 'Fregean Monism' (FM), to better account for the property differences between the constituting and constituted objects without the need to regard them as two distinct objects. On the FM view, the puzzle of material constitution as partly a semantic puzzle and partly a metaphysical puzzle, and shows how a solution to the semantic part of the puzzle, based on the Fregean distinction between sense and reference, can yield a satisfactory solution to the metaphysical part of the puzzle. The key idea is that while the reference of a term picks out both the referent object and its referent properties and thereby addresses the metaphysical part of the puzzle, the sense of the term determines which referent properties of the referent object are picked out and thereby addresses the semantic part of the puzzle.

In what follows, I shall outline the puzzle of material constitution, explicate the Fregean-Monist solution to the puzzle, show how this solution can address pluralist criticisms against monism, and critically evaluate the master argument employed by pluralists - the argument from Leibniz's Law, before concluding that the property differences between the constituting and constituted objects can be accounted for without the need to regard them as two distinct objects.

\section{The puzzle of material constitution}

The puzzle of material constitution can be illustrated through the example of the piece of bronze and the bronze statue. Suppose that, on Monday, a sculptor purchases an unformed piece of bronze, which he names 'Lump'. Suppose further that, on Tuesday, he sculpts the bronze into the form of king David and names it 'David.' Monists claim that the sculptor possesses only 
one object, for David is identical to Lump because they are materially and spatially coincident. Yet, pluralists claim that Lump and David differ in various respects. First, Lump and David differ in their temporal properties: Lump existed on Monday, David did not. Second, Lump could survive being squashed, David could not. Third, they differ in kind: Lump is a piece of bronze, David is a bronze statue. They claim that if Lump and David differ in even one way, they are not identical, for Leibniz's Law tells that for any $\mathrm{x}$ and $\mathrm{y}$, if $\mathrm{x}$ and $\mathrm{y}$ are distinct then there is at least one property that $\mathrm{x}$ has and $\mathrm{y}$ does not, or conversely, for any $\mathrm{x}$ and $\mathrm{y}$, if $\mathrm{x}$ and $\mathrm{y}$ are identical, then $\mathrm{x}$ and $\mathrm{y}$ share all of the same properties. Thus, they conclude that the sculptor possesses two objects: a bronze statue and a piece of bronze. More generally, pluralists claim that there must be two material objects existing in the same place at the same time because they do not share all of the same properties. Moreover, pluralists claim that two material objects can exist in the same place at the same time because they are objects of a different kind.

On the contrary, monists claim that spatially coincident objects are impossible. Wiggins (1968) calls the monist claim - that two things cannot completely occupy exactly the same place or exactly the same volume for exactly the same period of time - a truism. L.A. Paul (2010) neatly summarises the monist arguments for constitution as identity. First, monists can claim that any differences in essence or other properties between David and Lump are only apparent; they are just differences in description based on different contexts. For example, we call the object 'David' when we ascribe an essence including being statue-shaped and having aesthetic appeal and we call it 'Lump' when we ascribe a different essence and properties such as its chemical structure and what it is suited to build. In other words, the property differences between the constituting and constituted objects are only skin-deep; they are context-dependent rather than observer-independent features of the world. Second, monists can claim that their view is simpler and that the pluralist view fills reality with layer upon layer of excess ontological fat (Bennett 2004). We can adopt a leaner and meaner view by identifying the constituting and constituted objects, just as a picture is just an arrangement of pixels on paper (Lewis 1994). More generally, we can view the apparent incompatibilities of properties as simply the consequence of incompatibilities in perspective or description. 


\section{Towards a Fregean-Monist solution to the puzzle of material constitution}

Perhaps a useful first step to navigate a way through the tortuous puzzle of material constitution is to spell out the agreements between the monists and the pluralists. First, both sides agree that the constituting and constituted objects are materially and spatially coincident but disagree on whether they are identical. Second, both sides agree that the puzzle of material constitution has a semantic aspect. While most monists claim that any differences in essence or other properties between the constituting and constituted objects are only apparent, or are differences in description based on different contexts, most pluralists claim that the choice to include objects into or exclude objects from our ontological scheme is based on whether certain sortal terms exist in ordinary language. Perhaps an adequate solution to the puzzle of material constitution is in part semantic and in part metaphysical.

The next step is to highlight the most plausible elements of both monist and pluralist positions. Even if we reject the monists' claim that the property differences between the constituting and constituted objects are only skin-deep or context-dependent, we need not reject their aim to trim excess ontological fat off the pluralists' account. That is, the monist account has the principle of parsimony on its side as it has the simpler explanation of material constitution involving the fewest entities, provided that its explanatory power is not inferior to that of the pluralist account. And even if we reject the pluralists' claim that there are two or more objects occupying the same place at the same time for the sake of parsimony, we need not reject their aim to account for property differences. That is, the pluralist account has the virtue of saving appearances on its side as it aims to explain the way things seem like to us, what Lynn Rudder Baker calls 'a metaphysics of ordinary things' (Baker 2008).

Keeping the first two steps in mind, the third step is to define the concepts of object and property since they are key to resolving this puzzle. A definition offered by C.B. Martin and John Heil, which I endorse, is as follows: 'Objects can have parts, but an object's properties are not its parts, they are the particular ways the object is' (Martin and Heil 1999, 45). When 
material parts are arranged, organised, or structured in certain ways (in the static sense), or when material parts connect, interact or enter into processes with one another in certain ways (in the dynamic sense), then the object constituted by these material parts bear certain properties. Objects can be treated as concrete particulars while properties can be treated as abstract particulars, distinct from and yet grounded on objects or concrete particulars. Different terms can be used to represent a single object or concrete particular in different ways, including or excluding certain properties or abstract particulars. For example, the term 'Lump' can be used to represent a bronze object, or a chunk of bronze parts arranged in a certain way occupying a certain place at a certain time, including some of its the properties (weight and size) but excluding others (statue-shape and aesthetic appeal). And the term 'David' can be used to represent the same bronze object, or the same chunk of bronze parts arranged in the same way, including more of its properties than 'Lump' (weight, size, statue-shape, and aesthetic appeal).

I shall call this view Fregean Monism (FM) since it is largely based on Frege's famous distinction between reference (extension) and sense (intension) with a few modifications. FM is based on the following claims:

i. Terms refer to objects and their properties.

ii. Terms have reference (extension) and sense (intension). The reference (extension) of a term picks out an object and its properties; the sense (intension) of the term determine which properties of the object are picked out.

iii. Referent objects are objects picked out by their corresponding terms; referent properties are properties picked out by their corresponding terms.

iv. Referent objects are concrete particulars (arrangements of material parts); referent properties are abstract particulars (ways arrangements of material parts are).

v. Two or more terms can have the same reference or referent object.

vi. Even when two or more terms have the same reference (pick out the same referent object), they can have different senses (pick out different referent properties of that referent object). For example, 'David' picks 
out properties including weight, size, statue-shape and aesthetic appeal whereas 'Lump' picks out properties such as weight and size but not statue-shape and aesthetic appeal, even when both terms refer to the same object - the bronze piece.

On this view, semantic pluralism (the linguistic component of the view) explains property pluralism (the metaphysical component of the view). While 'David' and 'Lump' refer to the same object or concrete particular, the properties or abstract particulars picked out by 'David' and 'Lump' are different because of their different senses. While the senses of both 'David' and 'Lump' pick out the weight and size of the object, the sense of 'David' but not 'Lump' picks out its statue-shape and aesthetic appeal. Unlike other versions of monism, FM explains the monists' intuition that materially and spatially coincident objects are identical without explaining away property differences as mere differences in description, perspective, or context. And unlike pluralism, FM explains the pluralists' intuition about property pluralism without appealing to object pluralism.

To explain property pluralism, FM posits two kinds of reference - referent objects and referent properties. While reference (extension) picks out both the referent object and its referent properties and accounts for the metaphysics, sense (intension) determines which referent properties of the referent object are picked out and accounts for the semantics. This conceptual distinction provides a solution to the puzzle of material constitution, which could have arisen because terms do not pick out all of the referent properties of a referent object. And as terms do not pick out all of the referent properties of a referent object, different terms represent the referent object in a different and partial way by picking out some of its referent properties but not others. As such, FM is not only a semantic solution, but also a metaphysical one. It does not explain away differences in properties as mere differences in description, perspective, or context. Instead, it explains why a referent object can seem to have different referent properties by showing how different terms pick out some but not all of the referent properties possessed by the referent object. 


\section{Pluralist arguments against monism and Fregean-Monist responses}

The first argument pluralists employ against monists is the argument from Leibniz's Law (Fine 2003; Frances 2006). According to this argument, David and Lump cannot be one and the same object because there is at least one difference between them, and by holding that David and Lump are one and the same object despite their property differences, monism violates Leibniz's Law. Yet, Leibniz's Law is not violated when the property differences are accounted for by different terms picking out the different properties of one and the same object, as terms referring to one and the same object pick out some but not all of its properties. An object is called 'David' when its aesthetic appeal is picked out and called 'Lump' when its aesthetic appeal is not picked out. Like other monists, proponents of FM assume that there is only a single object, a piece of bronze, occupying a place at a time, being referred to as 'David' or 'Lump.' But unlike other monists, proponents of FM tell a deeper story by emphasising that 'David' and 'Lump' have the same referent object but different referent properties. And the senses of 'David' and 'Lump' determine which referent properties are picked out. FM shows how the semantic difference explains the ontological difference. On this view, the aesthetic appeal of the piece of bronze is not merely a way of describing the piece of bronze within a certain context (a predicate); it also picks out the way the piece of bronze is under certain circumstances (a property). In other words, aesthetic appeal is possessed by the piece of bronze but it is picked out by the sense of 'David' but not the sense of 'Lump.' Thus, FM does not violate Leibniz's Law by explaining property differences in terms of different terms picking out the different properties of one and the same object, as terms referring to one and the same object pick out some but not all of its properties.

The second related argument pluralists employ against the monists is the argument from different persistent conditions between the constituting and constituted objects (Baker 1997, 2000). On the pluralist view, David ceases to exist as the constituted object should it lose its essential/fundamental property - aesthetic appeal - by losing its statue-shape while Lump persists as the constituting object. Yet, everything else about David remains 
intact other than its aesthetic appeal. Why, then, hold that David as an object or concrete particular, ceases to exist? On other versions of monism, 'David' is just a different description of 'Lump' from another perspective or in another context. In other words, the difference between the constituting and constituted objects is merely semantic. However, there is also an ontological difference between them, for what cease to exist are properties or abstract particulars (aesthetic appeal), even if the object or concrete particular (bronze object) persists. On the FM view, different terms designating the same referent object pick out different referent properties. When a certain referent property (aesthetic appeal) of a referent object (bronze object) no longer exists, the term ('David') that picks out the lost referent property (aesthetic appeal) no longer applies. To borrow Aristotle's examples, an eye remains numerically the same eye after losing its sight and an axe remains numerically the same axe after losing its sharpness. At most, it can be argued that the term 'axe' that picks out the lost referent property, sharpness, is no longer applicable to the now blunt axe-shaped object, or that the term 'eye' that picks out the lost referent property, sight, is no longer applicable to the now blind eye-shaped object. And perhaps other terms can be used to pick out the blunt axe-shaped object or the blind eye-shaped object. But it is another thing to argue that an axe, as an object, ceases to exist when it becomes blunt or an eye, as an object, ceases to exist when it becomes blind, when the material parts arranged axe-wise or eye-wise respectively, still occupy the same place at the same time. Hence, the appearance of two materially and spatially coincident objects with different persistence conditions can be explained as two different terms picking out the same referent object but different referent properties.

The two above pluralist arguments can be re-expressed as a reductio argument against monism. According to this argument, holding that the constituting and constituted objects are a single object implies that it both possesses and lacks a property such as aesthetic appeal, or that it both exists and not exists at the same time, and hence results in a contradiction. This argument works only on the assumption that property pluralism implies object pluralism, an assumption challenged by the proponents of FM. On the FM view, the constituting object (Lump) and the constituted object (David) are not two different referent objects but two different terms 
('Lump' and 'David') picking out different referent properties of the same referent object (bronze object). The bronze object is called 'David' when aesthetic appeal is present and is called 'Lump' when aesthetic appeal is absent. And the bronze object can gain aesthetic appeal and be called 'David' or lose aesthetic appeal and be called 'Lump.' It is not the case that a new object (David) comes into existence and coincides with an existing object (Lump) after gaining a new property (aesthetic appeal) and goes out of existence and no longer coincides with the existing object (Lump) after losing the new property (aesthetic appeal). In other words, it is not the case that some properties possessed by Lump are not possessed by David and vice versa. On the contrary, it is the case that David and Lump are a single object referred to by two different terms with the same extension but different intensions that pick out some but not all the referent properties. Hence, there is no contradiction in holding that the constituting and constituted objects are a single object and the reductio argument does not succeed.

The third argument pluralists employ against the monists is the argument from primary kinds. Originating from Aristotle, an object's primary kind defines what it is essentially or fundamentally (Baker 2002, 2008). For example, a statue (David) is a different kind of object from a piece of bronze (Lump) as the former is essentially an art object whereas the latter is essentially a piece of raw material. So, how many objects there are in the same place at the same time depends on how many kinds of objects there are. Monists object that the notion of primary kinds is not without problems. First, postulating how many kinds of materially and spatially coinciding objects there are remains arbitrary as it is contingent upon our epistemic interests and linguistic conventions. Second, the correspondence between the sortal terms in our language and the kinds of objects in the world requires further explanation and the decision to include some kinds and exclude others requires further justification (Wilson 2007). For these reasons, FM treats primary kinds as conceptual categories rather than ontological categories, like other forms of monism. Unlike other forms of monism, however, FM shows how the semantic pluralism of primary kind terms account for their property pluralism without resorting to object pluralism. On the FM view, different primary kind terms are employed to look at 
a single object in different ways, including or excluding certain properties, rather than to pick out distinct materially and spatially coincident objects because of differing properties. That is, different primary kind terms, with different senses, pick out different properties of a single object instead of different objects. Categorising a piece of bronze as a statue kind (David) is seeing it inclusive of its aesthetic appeal and categorising the same piece of bronze as a raw material kind (Lump) is seeing it exclusive of its aesthetic appeal. Thus, primary kinds need not be ontological categories that pick out different objects because they do not share all of the same properties; they can be conceptual categories that pick out different properties of a single object.

On the FM view, objects are concrete particulars, consisting of only their material parts and arrangement, implying that only one object can occupy one place at a time. This definition rules out the pluralist claim that more than one object of different primary kinds can be in the same place at the same time, with one object belonging to a primary kind constituting a second object belonging to another primary kind, as materially and spatially coinciding objects of different kinds cannot count as more than one concrete particular. To claim that materially and spatially coincident objects are distinct objects, pluralists need to deny that all materially and spatially coincident objects are concrete particulars. There are at least two ways pluralists can do so. The first way is to claim that some of these objects are abstract and that concrete and abstract objects can be materially and spatially coincident. Yet, the distinction between abstract and concrete objects is usually taken to mean the type-token or universal-particular distinction, and pluralists would not want to claim that a piece of bronze is a tokenparticular of a statue type-universal. The second way is to claim that some objects are immaterial and that material and immaterial objects can be materially and spatially coincident. Yet, pluralists would not want to claim that statues are immaterial either. So, if objects are concrete particulars that consist only of their material parts and arrangements, then not more than one object can occupy a place at a time. And if not more than one object can occupy a place at a time, then it is more plausible to treat property differences between constituting and constituted objects as different properties of a single object picked out by different terms with different senses. 


\section{A closer look at the argument from Leibniz's Law}

In the earlier section, I have argued that FM does not violate Leibniz's Law. In this section, I want to show that Leibniz's Law does not necessarily support object pluralism. Let us look at a version of Leibniz's Law (adapted from King 2006 and Smid 2017) more thoroughly:

\begin{tabular}{|c|c|c|}
\hline Premise (1) & $\mathrm{F}(\mathrm{t})$ & $\longrightarrow$ (Property Pluralism) \\
\hline Premise (2) & $\neg \mathrm{F}(\mathrm{s})$ & \\
\hline Conclusion (1) & $\therefore \mathrm{t} \neq \mathrm{s}$ & $\longrightarrow$ (Semantic Pluralism) \\
\hline Premise (3) & $\mathrm{t} \rightarrow \mathrm{y} \&$ & $\rightarrow \mathrm{x}$ \\
\hline
\end{tabular}

Conclusion $(2) \quad \therefore \mathrm{y} \neq \mathrm{x} \longrightarrow$ (Object Pluralism)

where ' $\mathrm{F}$ ' is a predicate expressing a property, 's' and ' $\mathrm{t}$ ' are terms (names and definite descriptions) expressing objects, ' $\mathrm{x}$ ' and ' $\mathrm{y}$ ' denote objects, and ' $\rightarrow$ ' denotes 'picks out/refers to.'

Applying this to the case of David and Lump, where $\mathrm{F}=$ aesthetic appeal, $\mathrm{t}=$ 'David' and $\mathrm{s}=$ 'Lump,' $\mathrm{y}=$ David the bronze statue, $\mathrm{x}=$ Lump the piece of bronze, we have:

Premise (1a) 'David' possesses the intension/sense of aesthetic appeal.

Premise (2a) 'Lump' lacks the intension/sense of aesthetic appeal.

Conclusion (1a) Therefore, 'David' is not identical to 'Lump'.

Premise (3a) 'David' has David (the bronze statue) as its extension/referent and 'Lump' has Lump (the piece of bronze) as its extension/referent.

Conclusion (2a) Therefore, David (the bronze statue) is not identical to Lump (the piece of bronze).

Proponents of FM affirm premises (1) and (2) and conclusion (1). They affirm that term $\mathrm{t}$ has the intension/sense of property $\mathrm{F}$ whereas term $\mathrm{s}$ does 
not, and hence terms $\mathrm{t}$ and $\mathrm{s}$ are not semantically identical terms. At this stage, whether $t$ and s refer to one or two objects remains undetermined. In other words, only semantic pluralism, but not object pluralism, is ascertained. Proponents of FM also deny premise (3) and conclusion (2). They deny object pluralism, held by the pluralists, that the terms $t$ and $s$ pick out distinct objects y and $\mathrm{x}$ respectively. Does the denial of object pluralism violate Leibniz's Law? I contend that it does not, because Leibniz's Law says nothing about whether premise (3), the claim that the terms $\mathrm{t}$ and s pick out distinct objects y and x respectively, holds. And I further contend that since Leibniz's Law remains silent on whether premise (3) is true, pluralists cannot rely on premise (3) to derive conclusion (2). Therefore, Leibniz's Law does not necessarily support object pluralism.

Since pluralists cannot appeal to Leibniz's Law to justify premise (3) without begging the question, other independent arguments are required. That is, pluralists have to show that objects $\mathrm{y}$ and $\mathrm{x}$ are the referents picked out by the terms $\mathrm{t}$ and $\mathrm{s}$ respectively before they can conclude that $\mathrm{y}$ is not identical to $\mathrm{x}$. Otherwise, premise (3) remains a contested assumption or mere stipulation. Perhaps the strongest pluralist argument for premise (3) is the argument from primary kinds, the idea that while objects of the same kind cannot occupy the same place at the same time, objects of different kinds can. Yet, as mentioned above, the argument from primary kinds remains problematic. First, postulating how many kinds of materially and spatially coinciding objects there are still seems arbitrary as it is contingent upon our epistemic interests and linguistic conventions, Second, the correspondence between the sortal terms in our language and the kinds of objects in the world requires further explanation and the decision to include some kinds and exclude others requires further justification. Hence, since the pluralists' appeal to the argument from primary kinds to support premise (3) remains contested, and premise (3) is required for conclusion (2), then the pluralists' appeal to Leibniz's Law to support conclusion (2) remains contested.

On the contrary, FM offers a plausible argument for denying the contested premise (3) and conclusion (2). First, objects, such as $\mathrm{x}$ and $\mathrm{y}$, are concrete particulars and since concrete particulars are defined only by their material parts, arrangement, and location and $\mathrm{x}$ and $\mathrm{y}$ share exactly the 
same material parts, arrangement, and location, then $\mathrm{x}$ and $\mathrm{y}$ are numerically identical; they are a single object. Despite affirming the material and spatial coincidence of $\mathrm{x}$ and $\mathrm{y}$, pluralists insist that they are two objects instead of one because of the property differences between them. In contrast, FM explains the property differences $\mathrm{x}$ and $\mathrm{y}$ without resorting to an object difference. Second, terms s and t need not pick out two distinct referent objects y and x. Instead, they may pick out the same referent object, say $\mathrm{z}$, but pick out different referent properties of z. For example, $\mathrm{t}$ may pick out referent property $\mathrm{F}$ but s may not, even when s and $t$ pick out the same referent object $\mathrm{z}$. That is, $\mathrm{t}$ and $\mathrm{s}$ have the same extension/referent but different intension/sense: the term $\mathrm{F}(\mathrm{t})$ represents object $\mathrm{z}$ with property $\mathrm{F}$ and the term $\neg \mathrm{F}$ (s) represents object $\mathrm{z}$ without property $\mathrm{F}$. While the pluralist view holds that object pluralism is required to account for property pluralism, FM claims that semantic pluralism can account for property pluralism - an ontological difference - without object pluralism. Third, FM is not claiming that $\mathrm{z}$ both possesses and lacks F, but that $\mathrm{z}$ can be represented in two ways, with or without $\mathrm{F}$, by using the terms $\mathrm{t}$ and $\mathrm{s}$ respectively. It treats primary kinds as conceptual instead of ontological categories. Classified under one kind, z can be represented as F(t) and classified under another kind, z can be represented as $\neg \mathrm{F}$ (s). On the FM view, only one concrete particular, or a particular arrangement of material parts, occupies a place at a time, represented in different ways using different terms, or classified under different kinds, including or excluding certain abstract particulars.

Applying this analysis to the David and Lump case, 'David' and 'Lump' are two names for a single object - a particular arrangement of bronze parts. The term 'David' is used to denote it when it is represented as an art object (falls under the statue kind/category), with its aesthetic appeal; the term 'Lump' is used to denote it when it is represented as a piece of raw material (falls under the raw material kind/category), without its aesthetic appeal. When this particular arrangement of bronze parts retains its aesthetic appeal, it can be denoted by both 'David' and 'Lump' as it falls under both the statue and raw material kinds/categories. But when it loses its aesthetic appeal for some reason, then it can only be denoted by 'Lump' but not 'David' as it no longer falls under the statue kind/category even if it still 
falls under the raw material kind/category. There is only one object all along, denoted by different terms picking out different properties. So, on the FM view, David and Lump are numerically identical; they are a single bronze object capable of bearing all the properties ascribed to both David and Lump by the pluralists at certain times but not others, and is called 'David' or 'Lump' accordingly, depending on whether it possesses/gains or lacks/loses aesthetic appeal.

Pluralists may object that FM, like other versions of monism, changes the puzzle of material constitution from an ontological problem to a mere semantic problem, or reducing 'a metaphysics of everyday things' to merely 'a description of everyday things.' In the above analysis of Leibniz's Law, for example, proponents of FM seem to change the discussion from one about objects ( $\mathrm{x}$ and $\mathrm{y}$ ) and properties $(\mathrm{F})$ to one about subjects and predicates $(\mathrm{F}(\mathrm{t}))$ and $(\neg \mathrm{F}(\mathrm{s}))$. This is not the case, however. Proponents of FM apply a semantic tool, the distinction between the sense and reference of terms, to clarify, not dismiss, the ontological part of the puzzle. While the reference of a term ( $\mathrm{t}$ or $\mathrm{s})$ picks out an object $(\mathrm{z})$ and its properties $(\mathrm{F})$, the sense of a term determines which of the object's ( $z$ 's) properties are picked out and which are not. Both terms, $t$ and $s$, pick out object $z$, but whereas $\mathrm{F}(\mathrm{t})$ pick out property $\mathrm{F}, \neg \mathrm{F}(\mathrm{s})$ does not. Again, assuming that terms 'David' and 'Lump' refer to a single bronze object, 'David' represents the bronze object (inclusive of its aesthetic appeal) as an art object whereas 'Lump' represents the same bronze object (exclusive of its aesthetic appeal) as a piece of raw material. Proponents of FM treat referent properties or abstract particulars as ways referent objects or concrete particulars are, and not merely ways referent objects or concrete particulars are described or represented. In other words, claims about referent properties are claims about ways referent objects are. They are ontological claims, not merely semantic ones. As proponents of FM employ semantic tools to clarify rather than dismiss ontological claims, the objection that FM changes the puzzle of material constitution from an ontological problem to a mere semantic problem is unwarranted.

Moreover, pluralists may object that proponents of FM have not clearly shown that the terms $\mathrm{t}$ and $\mathrm{s}$ refer to a single object, $\mathrm{z}$ and not two objects, $\mathrm{x}$ and $\mathrm{y}$. Yet, the various arguments presented above, in tandem, offer good 
reasons in favour of the claim that $\mathrm{t}$ and s refer to a single object. First, the claim that - if $\mathrm{x}$ and $\mathrm{y}$ are materially and spatially coincident then they are identical objects - remains a truism despite being challenged. As argued above, the challenges presented by both the argument from Leibniz's Law and the argument from different primary kinds remain inconclusive. Second, the claim that - if $\mathrm{x}$ and $\mathrm{y}$ do not share property $\mathrm{F}$, then they cannot be identical objects - remains questionable. As argued above, whether object $\mathrm{z}$ possesses/gains or lacks/loses property $\mathrm{F}$ does not imply that it must therefore be two distinct objects $\mathrm{x}$ and $\mathrm{y}$, it may just be two different ways of presenting object $\mathrm{z}$, with or without property $\mathrm{F}$, using terms $\mathrm{t}$ and $\mathrm{s}$ respectively. Third, the monist claim that $\mathrm{t}$ and $\mathrm{s}$ refer to a single object has the principle of parsimony on its side so long as it explains appearances as well as the pluralist claim that $\mathrm{t}$ and $\mathrm{s}$ refer to two distinct objects. As argued above, FM does not explain away the qualitative difference between $\mathrm{x}$ and $\mathrm{y}$ as simply differences in description, perspective, or context. Rather, it tells a deeper story about how the qualitative difference is dependent on whether referent property $\mathrm{F}$ is picked out by terms $\mathrm{t}$ or $\mathrm{s}$. Therefore, the reasons in favour of the monist claim seem stronger than those in favour of the pluralist one.

\section{Conclusion}

The puzzle of material constitution is in part ontological and in part semantic and an ideal solution to the puzzle of material constitution should address both ontological and semantic issues and possess the twin virtues of parsimony and saving appearances. FM is one such attempt. First, by holding that objects are concrete particulars or arrangements of material parts and that only one concrete particular or arrangement of material parts can occupy a place at a time, FM preserves the virtue of parsimony, unlike pluralism. Second, by distinguishing between properties as ways objects are (ontological category) and terms as ways objects are described or represented (semantic category), FM does not explain away property differences as mere differences in description, perspectives, and context, but explain the property differences by applying a semantic tool, the distinction be- 
tween the sense and reference of terms, to clarify, not dismiss, the ontological part of the puzzle, unlike other versions of monism. Third, by maintaining that the reference (extension) of a term picks out an object and its properties, and that the sense (intension) of the term determines which properties of the object are picked out, FM explains why a referent object can seem to have different referent properties by showing how different terms pick out some but not all of the referent properties possessed by the referent object, thus preserving the virtue of saving appearances, unlike other versions of monism. Fourth, in accepting property pluralism and rejecting object pluralism, FM does not violate Leibniz's Law. And as Leibniz's Law remains silent on whether two semantically distinct terms pick out two objects or a single object (partially) represented in different ways, it does not necessarily support object pluralism. Fifth, to support a metaphysics of ordinary things, it seems sufficient to have different terms picking out different referent properties of a single referent object occupying a place at a time rather than to have more than one materially and spatially coinciding referent objects. These points make FM worth-considering as a solution to the puzzle of material constitution.

\section{References}

Baker, Lynne Rudder. 1997. "Why Constitution is Not Identity." The Journal of Philosophy 94 (12): 599-621.

Baker, Lynne Rudder. 2000. Persons and Bodies: A Constitution View. Cambridge: Cambridge University Press.

Baker, Lynne Rudder. 2002. "On Making Things Up: Constitution and its Critics." Philosophical Topics 30 (1): 31-51. https://doi.org/10.5840/philtopics200230112

Baker, Lynne Rudder. 2008. "A Metaphysics of Ordinary Things and Why We Need It." Philosophy 81 (1): 5-24. https://doi.org/10.1017/S0031819108000284

Bennett, Karen. 2004. "Spatio-Temporal Coincidence and the Grounding Problem." Philosophical Studies 118 (3): 339-71. https://doi.org/10.1023/B:PHIL.0000026471.20355.54

Fine, Kit. 2003. "The Non-Identity of a Material Thing and its Matter." Mind 112 (446): 195-234. https://doi.org/10.1093/mind/112.446.195

Frances, Bryan. 2006. "The New Leibniz's Law Arguments for Pluralism." Mind 115 (460): 1007-1021. https://doi.org/10.1093/mind/fzl1007 
Frege, Gottlob. 1892. "On Sense and Reference." ["Über Sinn und Bedeutung".] Zeitschrift für Philosophie und philosophische Kritik 100: 25-50.

Gibbard, Allan. 1975. "Contingent Identity." Journal of Philosophical Logic 4 (2): 187-221. https://doi.org/10.1007/BF00693273

King, Jeffrey. 2006. "Semantics for Monists." Mind 115 (460): 1023-58. https://doi.org/10.1093/mind/fzl1023

Lewis, David. 1999. "Reduction of Mind." In Papers in Metaphysics and Epistemology, edited by David Lewis, 291-324. Cambridge: Cambridge University Press.

Martin, C.B. and Heil, John. 1999. "The Ontological Turn." Midwest Studies in Philosophy 23 (1): 34-60. https://doi.org/10.1111/1475-4975.00003

Paul, L.A. 2010. "The Puzzles of Material Constitution." Philosophy Compass 5 (7): 579-90. https://doi.org/10.1111/j.1747-9991.2010.00302.x

Smid, Jeroen. 2017. "Material Constitution is Ad Hoc." Erkenntnis 82 (2): 305-25. https://doi.org/10.1007/s10670-016-9818-6

Wasserman, Ryan. 2017. "Material Constitution." The Stanford Encyclopedia of Philosophy (Fall 2018 Edition), edited by Edward N. Zalta. Last updated July 5. 2017. https://plato.stanford.edu/archives/fall2018/entries/material-constitution

Wiggins, David. 1968. "On Being at the Same Place at the Same Time." The Philosophical Review 77 (1): 90-95. http://doi.org/10.2307/2183184

Wilson, Robert. 2007. "A Puzzle about Material Constitution \& How to Solve it: Enriching Constitution Views in Metaphysics." Philosophers' Imprint 7 (5): 120.

Zalta, Edward N. 2019. "Gottlob Frege." The Stanford Encyclopedia of Philosophy, (Fall 2020 Edition), edited by Edward N. Zalta. Last updated Dec 5. 2019. https://plato.stanford.edu/archives/fall2020/entries/frege 